\title{
A Programme Management Approach for Ensuring Curriculum Coherence in IS (Higher) Education
}

\author{
Hatzakis, T. \\ Brunel Business School \\ Brunel University, Uxbridge, Middlesex. UB8 3PH. \\ United Kingdom \\ \& \\ Lycett, M. and Serrano, A. \\ School of Information Systems, Computing and Mathematics \\ Brunel University, Uxbridge, Middlesex. UB8 3PH. \\ United Kingdom.
}

\section{Abstract}

This paper examines IS higher education, concentrating on issues of 'coherence' in IS curricula. While curriculum coherence can be jeopardized by poor curriculum design, misalignment between module content and/or misalignment between module or course aims can cause serious coherence issues over time. Misalignment of this type is exacerbated by the traditional processes of curriculum (re)design, which rely heavily on the (singular) interpretation of highly abstract documents, such as module syllabi and course specifications - often produced by curriculum designers in isolation. To improve curriculum coherence, this paper examines the use of a programme management framework as a means of (a) 'humanizing' the abstract aims and goals of curricula schemes and (b) managing the delivery and evolution of curricula in relation to the stakeholders in the process of delivery. The practical use of the framework is examined in the context of a Masters-level course in 'Information Systems Management'. An action research approach is used to demonstrate the practical utility of the framework in terms of (a) improving communication of curricula, (b) improving the coherence between modules and between modules and course and (c) removing content redundancy. Guidelines are presented that generalize the findings in order that key practices may be adopted by others. 


\title{
Programme Management as a Tool for Maintaining Curriculum Coherence in IS (Higher) Education
}

\begin{abstract}
This paper examines IS higher education, concentrating on issues of 'coherence' in IS curricula. While curriculum coherence can be jeopardized by poor curriculum design, misalignment between module content and/or misalignment between module or course aims can cause serious coherence issues over time. Misalignment of this type is exacerbated by the traditional processes of curriculum (re)design, which rely heavily on the (singular) interpretation of highly abstract documents, such as module syllabi and course specifications - often produced by curriculum designers in isolation. To improve curriculum coherence, this paper examines the use of a programme management framework as a means of (a) 'humanizing' the abstract aims and goals of curricula schemes and (b) managing the delivery and evolution of curricula in relation to the stakeholders in the process of delivery. The practical use of the framework is examined in the context of a Masters-level course in 'Information Systems Management'. An action research approach is used to demonstrate the practical utility of the framework in terms of (a) improving communication of curricula, (b) improving the coherence between modules and between modules and course and (c) removing content redundancy. Guidelines are presented that generalize the findings in order that key practices may be adopted by others.
\end{abstract}

\section{Introduction}

Despite the potential importance of curricula coherence for the preparation of prospective IS managers for their future careers, the development and delivery of coherent curricula (i.e., curricula that provides an integrative learning experience) presents a major challenge for higher education. For those involved in curriculum development there is a minimum need to balance the perspective of pedagogic integrity with industrial/market needs, interest and value for prospective students etc. Additionally, for courses of study in Information Systems/Information Technology, curriculum designers face the additional challenges of responding to rapid changes in the state-of-the-art and the industrial restructuring brought about by globalisation and outsourcing (which has a strong influence on the skill requirements of different markets).

Existing literature acknowledges the value of aligning module content to module and course of study specifications and across modules within the same course of study to ensure curriculum coherence (Knight, 2001). Yet, most literature is static and prescriptive, focusing on the desired milestones and end results of the top-down alignment of: 
1. Planned curricula, schemes that encompass the goals, intentions and ideas encompassed, often documented as in reports, policy or other relevant documents for the sake of curriculum integration and alignment

2. Enacted curricula, the interpretation of these schemes by lecturers and other academic staff through module delivery to students, and

3. Experienced curricula, the curricula aims, objectives and content understood by students (Marsh \& Willis, 1999).

There is little in the way of support for dealing with the 'dynamics' of the interaction of the above, over time, however. The existing literature does not explicitly tackle the potential lateral misalignment of curricula, across modules within the same course of study, at either the levels described above or the dynamics of interaction (particularly in the IS/IT literature). This point is important; as our observation is that 'drift' is a relatively natural occurrence in curriculum design and management. Accepting that curricula are generally well planned, there is no guarantee that the enactment or the experience of that curricula will be as intended by the planner(s). Moreover, over time, courses of study can become fragmented as module leaders are replaced and/or individual changes are made to modules on the basis of year-onyear feedback (for example).

The contention of this paper is that difficulties related to the above challenge are exacerbated by the lack of an effective management framework. Accordingly, the objectives of this work are to describe the development of such a framework and report on the resulting guidelines for action for the various stakeholders in the curricula development and management process. We believe these outcomes to be particularly important for courses of study in IS/IT as the courses are often action-based and closely linked to the needs of industry (in theory). With the industry/academia relationship in mind, the framework itself is based on the emerging stateof-the-art in programme management and the outcomes are reported from an action research perspective. The object of the action research is the (re)development and effective management of 8 Masters-level courses of study all related to IS/IT. This paper concentrates specifically on a Masters in Information Systems Management, which was used as the pilot for the framework - the course in question provides a context where observable drift had occurred.

The paper is structured as follows. Section 2 examines the literature to distil the prevailing perspectives on curriculum development. Section 3 provides the rationale for, and an 
overview of, the programme management approach adopted. Section 4 describes the action research, discussing the drivers for change and the means by which the programme management framework was made operational. Section 5 evaluates the outcomes of the work and reviews the implications for theory and practice.

\section{Current perspectives on curriculum development}

The literature highlights two broad perspectives on curriculum development: (a) the rational view and (b) the evolving view. While each perspective conceptualizes curricula in different ways and focuses on different aspects of their development, both are concerned with the vertical alignment between planned, enacted and experienced curricula: Neither concentrates on the lateral coherence across module aims, objectives and content within the planned, enacted or experienced curricula. The remainder of this section reviews these two broad perspectives, in order to highlight their assumptions and implications for curriculum coherence that can inform research in real contexts.

\subsection{The Rational view and its implications for curriculum coherence}

The rational view can be characterized as a top down approach to curricula development. The view suggests a systemic approach where the goals of the course-of-study cascade down through curriculum instruction, student assessment and overall curriculum evaluation objectives against which performance can be measured (Knight, 2001; ASHE-ERIC, 2002). According to this view, curriculum is "a matter of inducting the student into disciplinary practices such that they can, if they wish, progress from student to master" (Parker, 2003p.532). The focal point of this view is the planned curricula. Emphasis is placed on goalsetting and evaluation in order to develop curriculum schemes that ensure the successful integration of module content within the curriculum (Parker, 2003; Knight, 2001).

At this planned curriculum level, goal-setting is assumed to be in agreement, almost by default, and processes of achieving these goals are supposed to be managed by professionals and experts in the know, who can control processes effectively in isolation (Adams, 1988). No advice on the process of designing courses is offered from the perspective of ensuring coherence. For example, analysis of three internationally known IS-related, curricula schemes offered no pedagogical guidelines for course design, no educational principles for teaching and leaning to ensure the alignment of module content and delivery, and no mechanisms for integrating different modules within the curriculum scheme in practice (Alford et al., 2004). 
At the enacted curricula level, the responsibility for curriculum coherence is left in the discretion of academics, such as programme leaders, course coordinators and lecturers, who are expected to interpret goals of the planned curricula and translate them into teaching and learning action (Marsh \& Willis, 1999). The techniques available for helping with the development of coherent enacted curricula, such as curriculum mapping (see: http://www.livjm.ac.uk/quality/progspec/PS\%20Guidelines.doc, for details), are generally outcome-based. These approaches make learning outcomes transparent to assessors and students alike and may expose misalignment, but give very little guidance to academics for achieving alignment in the first place or rectifying misalignment later on. Other advice on how to integrate curricula is often vague and generic, and thus itself open to interpretation (Knight, 2001). For example, the main steps in the alignment process, as defined by the Learning and Teaching Support Network (Biggs, 2002; Biggs, 2003), are:

- $\quad$ Defining the intended outcomes (the curriculum objectives)

- Choosing teaching/learning activities likely to lead to help and encourage students to attain these objectives

- Engaging students in these learning activities through the teaching process.

- Assessing students' learning outcomes using methods that enable students to demonstrate the intended learning and evaluating how well they match what was intended

- Arriving at a final grade, and perhaps in the case of formative assessment, giving feedback to help students improve their learning.

The coherence of the experienced curriculum is not explicitly discussed from this point of view. Instead, it is treated as the direct outcome of the successful integration between planned and enacted curricula, assuming that students are passive recipients of academics efforts and that academic staff are responsible for the success or failure of the curriculum. The issue of the lateral coherence is overlooked - the implicit assumption here being that integration across modules will be ensured by integrating the goals of each module to programme specifications (Knight, 2001). Despite these limitations, however, the rational view remains the dominant view of curricula development partly for historical reasons and partly due to the fact that quality assurance and other accreditation is implicitly based on these declarative curricula schemes (Parker, 2003). 


\subsection{The Evolving view of curricula development and its implication for curricula coherence}

Johnson and Ratcliff (2004) note that the rational view requires no active input from the student and does not account for their perceptions of the curriculum. In addition, some studies found that structural strategies often did not achieve their aims for coherence (see Awbrey, 2005). As an antidote, the evolving view emerged as a bottom-up approach to curricula development, which suggests the continuous engagement of different stakeholders in the development, review and change of academic curricula. Curriculum is conceptualized as a "series of encounters between students" (Parker, 2003p.532) and can be viewed as a process of orchestrating good learning processes that provide students with the 'means' for achieving desired learning outcomes (Knight, 2001).

With regards to curriculum coherence this view focuses on the enacted curricula. Coherence is 'engineered' by choosing encounters compatible with the material and ensuring that the distribution of these encounters against the set of modules within a course-of-study is sufficient and well-balanced (Parker, 2003). This view does not deny the need for content and goal integration of modules within programmes, but rather emphasizes the learning principles that should guide the development of enacted curricula (Van de Bor et al., 1995). In developmental terms, stakeholder participation is emphasized throughout the curriculum design process. General advice on how to foster and sustain changes in academic curricula (ASHE-ERIC, 2002) includes generic advice such as:

- Create trust by promoting open and honest communication about changes with academic staff and students (Farmer, 1999),

- $\quad$ Foster commitment and support for change from academic heads (Ewell, 1997),

- Involve major stakeholders, particularly those most resistance to change, in the planning and implementation process (Ewell, 1997),

- Design change in incremental ways, provide training to enable academics be more effective in the delivery of the new content (ASHE-ERIC, 2002) .

This advice presumes iteration and continuous interaction amongst stakeholders during curriculum planning, and beyond (Van de Bor et al., 1995). The aim here is to explicitly share assumptions and perceptions about various aspects of the curriculum in order to reconcile different views and therefore achieve a coherent understanding between 
stakeholders, during its design process. Integration is ensured by monitoring (a) the degree of participation, (b) the systematization of the design approach, and (c) the convergence of stakeholders' interests and approaches (Van de Bor et al., 1995). The concepts of curriculum integration and coherence are, therefore, core to the design of curricula.

Although this view emphasizes stakeholder participation and convergence of stakeholder interests as essential prerequisites for achieving curricula coherence, what remains vague is the process through which module content is aligned with a course-of-study and module specifications. With regard to the lateral coherence of curricula, the issue is indirectly tackled through the integration of interests and the reconciliation of views of different stakeholders.

\section{A strategic programme management perspective}

In summary, the planned curricula approach emphasizes the need for clearly defined and integrated module goals and objectives (i.e., coherence is planned), while the enacted curricula approach emphasizes the need for reconciled stakeholder views and interests (i.e., coherence is the outcome of the ongoing participation and involvement of different stakeholders). From the above review, it is clear that the approaches are not mutually exclusive. The challenge is in 'process' however, as implementation is frequently the graveyard of strategic change (Grundy, 1998). Static top-down approaches are often complemented by evolving ones in order to allow coherence to 'live and breathe' in line with change in the business (for example). - The effective fusion of approaches and, given one of the authors' industrial experiences in programme management, this was explored as a vehicle for effective fusion. In this paper, the portfolio of Masters courses in IS/IT is conceptualized as programme, and the actual courses themselves (of which there were 8), are conceptualized as projects.

As an outgrowth of project management, the fundamental goals of programme management can be categorized as twofold:

- Efficiency and effectiveness: Aspects of management that a proficient project manager should address, even in the cases where related projects are undertaken without overall co-ordination. It is believed that a general improvement in management efficiency and effectiveness can be achieved by taking an integrated approach to these particular aspects of management (Pellegrini, 1997; OGC, 1999; McElroy, 1996). 
- Business focus: The external alignment of projects with the requirements, goals, drivers and culture of the wider organization. These goals are associated with defining an appropriate direction for the constituent projects within a programme as well as for the programme as a whole (Grundy, 1998).

The application of programme management in practice is problematic however. Lycett et al. (2004) argue that where change is strategic in nature (i.e., has strong business focus) there is a clear requirement for a conceptualization of programme management that specifically addresses the following observations:

- Effective programme management is relationship-based. Programme management should focus on creating a context that enables project managers to be successful, facilitating the stakeholder relationships that support this. In the context of a changing environment, it is of vital importance to ensure an adequate ongoing connection between the projects within the programme and the wider organization if projects are to remain aligned with the overall drivers and strategic direction of the organization. Equally, it is an important part of the programme management role to facilitate effective relationships between the individual project managers within the programme in order to ensure that they work together effectively and remain collectively focused on the achievement of overall business benefit.

- Effective programme management needs to take into account power dynamics. Programme management is not always recognized as being in the best interests of individuals in positions of power. It is important to anticipate potential issues related to the perceived power dynamic between project sponsors, project managers the programme manager and manage the relationships accordingly. In the context of an academic programme these will most likely be the school or departmental managers, programme coordinators, module leaders, etc.

- Effective programme management enables adaptability in the context of a changing business environment. Programmes often develop incrementally rather than by design, which requires a dynamic and flexible view of the programme lifecycle and overall definition of the programme. By mapping the constituents of a programme against a series of high-level lifecycle states and monitoring and controlling the transitions between those states a focus on the high level understanding of the overall goals and direction of the programme can be maintained as well as a focus on how individual component projects contribute towards this. A programme lifecycle must provide a clear separation 
between the justification of individual projects within the programme and the justification of the programme as a whole. Individual projects may derive a proportion of their benefits case based on their contribution to a programme; the programme as a whole is justified on the basis of the cumulative benefits case of its confirmed component projects. Whilst change control is applied at the individual project level, the focus at the programme level should be on strategic alignment and business change management.

Figure 1, ties these relationship observations to the fundamental goals of programme management as set in an educational context - in essence, this defines the management framework. In the context of this diagram, it should be noted that 'business' refers to the University as a business.

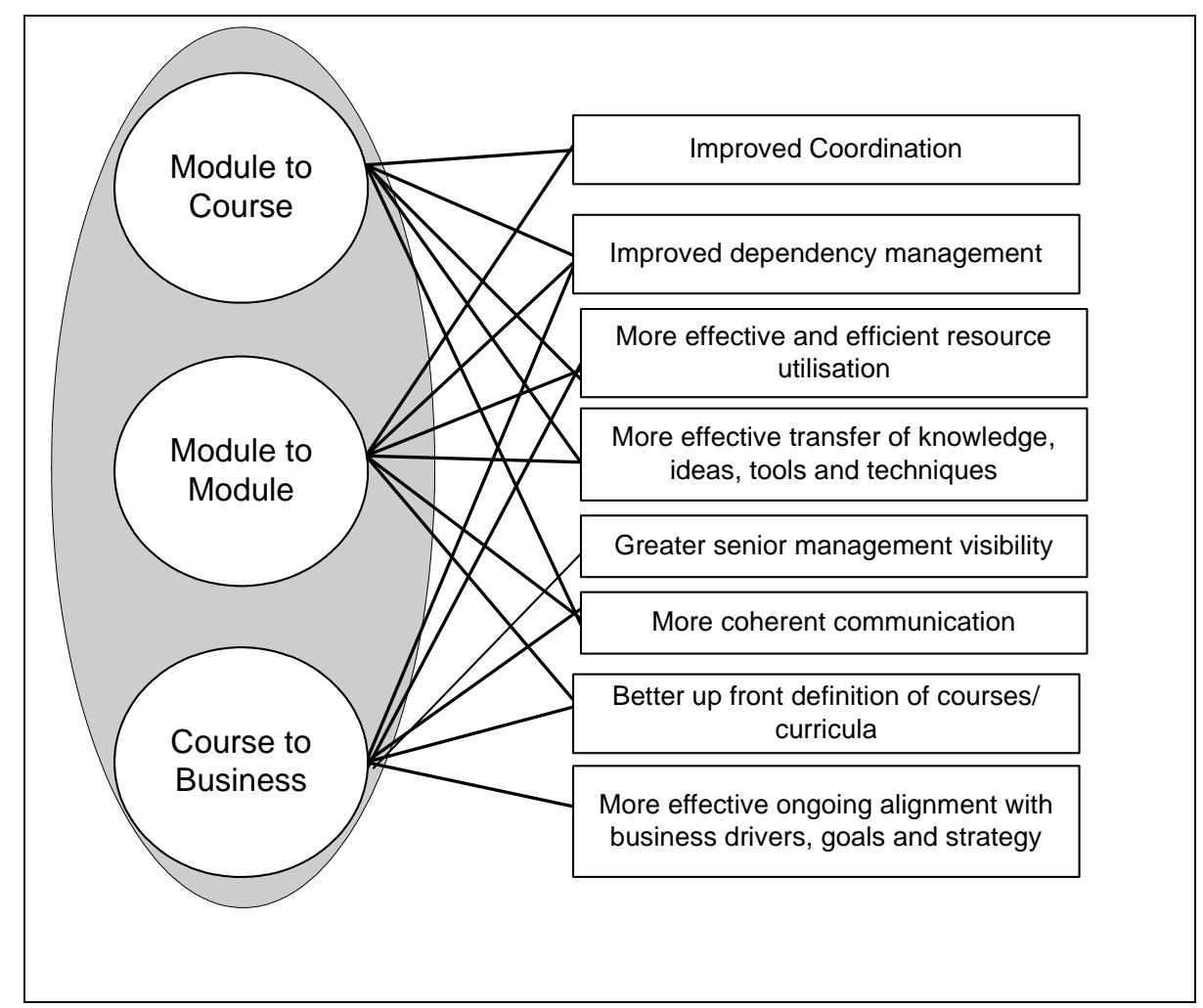

Figure 1. Programme Management Framework 


\section{An action research approach}

\subsection{Diagnosis}

The management framework was developed in response to organizational issues relating to curriculum design and management. A strategic review of Masters-level course provision undertaken in the Summer of 2003 identified the following drivers for change:

- Industrial restructuring. New ways of doing business have introduced changes in the needs of both home and overseas markets. For example, programming is now commonly seen as a commodity item, which is increasingly outsourced to markets such as India and South-East Asia. These markets are showing growth in the programming-related aspects of software engineering and IT-enabled services. In contrast, US and western European markets are showing growth in problem solving (e.g., business/systems analysis) and relationship-oriented job areas.

- Enhancing employability. Marketing analysis consistently notes employability as the primary reason for why students do Masters-level courses. Industrial stakeholders highlighted the need for enhanced skills including (a) training in team working, with real experience of team projects, alongside the development of (b) problem solving abilities, awareness of the need for life long learning, readiness to understand fully the needs of the customer and their project colleagues and awareness of cultural differences when acting in a global environment.

- $\quad$ Keeping pace with the state-of-the-art. Changes in perspectives, approaches, techniques and technologies in the information systems and computing area, which periodically require a module/course refresh.

- $\quad$ Programme focus. Course feedback demonstrated a need to provide a clear programme level focus, elucidating how modules relate from a course perspective to both the University and student perspective. Anecdotally, it appeared that lack of student 'engagement' was a problem that needed to be addressed at this level.

- University and Departmental strategy. Organisational strategy requires (a) that both student numbers grow and the proportion of overseas students grow and (b) that closer links are established with industry. 
- Teaching and Learning Strategy. The pedagogic perspective(s) of improving and differentiating Masters-level education and, in particular, establishing the Department as a centre-of-excellence for Masters-level education.

- $\quad$ Structure of the teaching year. The University was to move from a semester-based to a term-based structure from the academic year 2004/05, which required thought in relation to module assessment (one of two examination periods was removed).

These drivers were integrated with academic benchmarks such as the Framework for Higher Education Qualifications in England, Wales and Northern Ireland' produced by the United Kingdom Quality Assurance Agency. Changes that resulted from the mix involved both the redevelopment of existing courses and the addition of new courses. The remainder of the paper is set in the context of the MSc in Information Systems Management, as this course was one of the first to be redeveloped and selected for trial of the management framework.

Given the clear need to change the status quo, action research was adopted as the strategy of preference. as (a) the approach actively seeks to contribute to the resolution of the practical concerns of stakeholders in a problem situation and (b) the researchers were actively involved in the changes (Susman, 1983). For reference, the organizational roles of the authors were/are Director of Programme Development (Lycett), Course Manager (Serrano) and Research Fellow in Programme Development (Hatzakis). The form of action research used was most akin to the classification of clinical fieldwork, which dictates that (a) the process is client initiated, (b) the inquiry is client and problem-centred and (c) the data is drawn from client needs and perspectives (Schein, 1987). This form of action research is highly situational, typically has a linear process, is fluid in structure, facilitative in terms of involvement and has organizational development and knowledge acquisition as its primary goals. 


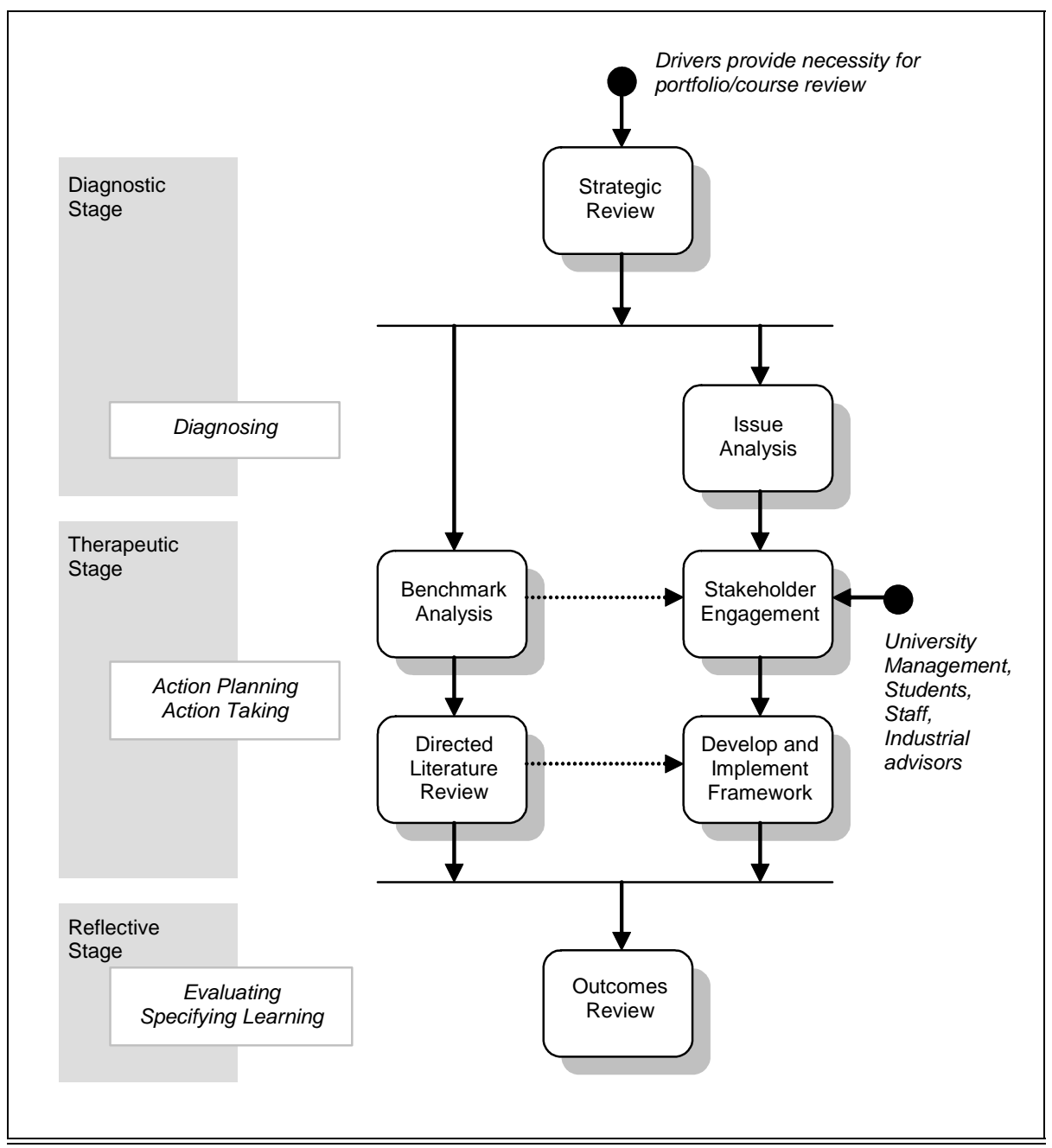

Figure 2. The Action Research Cycle

Following Sussman (1983), the action research was broadly dived into diagnostic, therapeutic and reflective stages as illustrated in Figure 2. The strategic review noted above was undertaken in the diagnostic stage and some causal analysis was undertaken to better understand the particular effects of the noted drivers on particular courses of study. In the therapeutic stage, a benchmark/market analysis was undertaken to ensure that resulting courses-of-study were (a) mindful of national and other benchmarking standards and relevant frameworks for higher education and (b) addressed the perceived needs of the market as noted in the strategic review. Selected stakeholders were also consulted at this stage in a variety of forms. For example, documented student feedback was examined and supplemented with selective focus group discussions. In addition, selective organizations were also consulted to provide a realistic 'feel' for what the IS/IT industry thought were/would be the major challenges they faced alongside the skill sets they perceived were needed to combat these 
challenges. Lastly, a literature review was conducted to ensure a good level of understanding in relation to the history and practice of curriculum design.

\subsection{Enacting the framework as therapy}

In essence, the diagnostic stage and the majority of the therapeutic stage provide a good example of the rational approach to curriculum planning. While valuable, this provided only half-an-answer as enacted and experienced curricula needed to be managed in a dynamic manner, with a view to providing 'evolving' feedback to the planned curricula. Three tools were used to 'manifest' the framework at an operational level:

1. Programme meetings. Whilst a seemingly 'obvious' solution, experience of the existing way of doing things demonstrated that communication, coordination and knowledge transfer at course and module level were areas where improvement could be achieved. Consequently, programme meetings were set-up on a rolling cycle (see Appendix A).

2. Action and audit process. Key actions were an outcome of the programme meetings, it was important that these were recorded, the action(s) taken and outcomes monitored (and/or a process defined for monitoring).

3. Staff development. Key observations of areas where improvements in general communication and knowledge transfer (for example) were required were translated into a staff development programme.

For clarity, Table 1 shows the mapping between the tools noted above and the framework goals illustrated in Figure 1. 


\begin{tabular}{|l|l|l|}
\hline Tools & Framework Goals & \multicolumn{2}{|l|}{ Issues with Programme Focus } \\
\hline Programme meetings & $\begin{array}{l}\text { Improved coordination } \\
\text { Improved dependency management } \\
\text { More effective transfer of knowledge etc. } \\
\text { More coherent communication }\end{array}$ & $\begin{array}{l}\text { Fragmentation of programme (lack of } \\
\text { knowledge and misunderstanding) } \\
\text { Content overlap } \\
\text { Misplacement of content in modules } \\
\text { Poor scope and timing of assessment } \\
\text { Need for audit and staff development }\end{array}$ \\
\hline Action and audit process & $\begin{array}{l}\text { Improved dependency management } \\
\text { Greater senior management visibility } \\
\text { More effective ongoing alignment }\end{array}$ & $\begin{array}{l}\text { Actions not being picked up upon for } \\
\text { future runs of a module } \\
\text { Opaque link between modules actions and } \\
\text { programme impact }\end{array}$ \\
\hline Staff development & $\begin{array}{l}\text { Improved coordination } \\
\text { More effective transfer of knowledge etc. } \\
\text { More coherent communication }\end{array}$ & $\begin{array}{l}\text { Lack of recognition of the role of modules } \\
\text { in relation to the programme aim and } \\
\text { outcomes } \\
\text { Content 'stuffing' and over-assessment }\end{array}$ \\
\hline
\end{tabular}

Table 1. Mapping of Tools to Framework Goals

As a refresh, there were a number of drivers for change to the course. From a planned perspective, the change was significant and the drivers converged with the aim of providing a clear programme focus. The outcome of the diagnostic stage was that 3 existing modules were withdrawn, 3 new modules were created, 3 modules were refocused in terms of content and title and only 2 modules remained unchanged. The next stage in the process was to manage the relationship between planned, enacted and experienced curricula using the programme management framework (in essence by continually achieving the framework goals) via the tools shown in Table 1. Once the curriculum had been re-planned, the Course Manager was appointed and an in-depth meeting held with the Director of Programme Development to start the process of 'institutionalising' the vision. In parallel, module leaders were appointed to develop and deliver content, which was prescribed to a given degree via learning outcomes and topics of study (contained in module syllabi documents).

Once module leaders had had time to develop their material, the cycle of programme meetings began (the details of which are noted in Appendix A). During the course of the meetings several issues emerged, some of which were present prior to the revamp (with the benefit of hindsight):

- Early signs of fragmentation were clear as one module clearly deviated from the planned curricula (this was clear in the study guide, a document given to students that provides a substantive expansion on the module syllabus).

- It was clear from both discussion and review of the study guides that (a) there was an overlap of content across modules and (b) some module content was misplaced. Analysis 
of the overlap issues was interesting. In some instances, the issue was simply one of redundancy and the module leader agreed to remove content from their module in deference to another. In other, instances, however, the material was not redundant as it was viewed from another perspective. So, for example, in one module Business Process Reengineering was approached from a normative perspective while, in another, the subject was approached from a critical perspective examining why normative approaches fail. The identification of alternative perspectives was extremely useful to module leaders as it allowed them to explicitly build links between modules that could be communicated to students (helping the perceived cohesion of the programme). Where content was misplaced, it was removed - analysis of this issue led to specific staff development as noted below.

- The scope, nature and timing of module assessments were also reviewed in programme meetings. Holistic analysis here uncovered issues in relation to both the scope and timing. In scope terms, it was found that modules of similar credit ratings made quite different demands on students. For example, one module was assessed wholly via a 5000 word essay, while another assessed via a 5000 word essay and a 2-hour examination. In timing terms, analysis showed that assessment deadlines often clashed and, in some instances, were inappropriately timed given their nature. Such issues were resolved by creating an assessment matrix and providing policy guidelines in relation to scope.

Several of the issues encountered pointed to a need to improve the action and audit processes employed and to run staff development in specific areas. Traditional practice, for example, expected that module leaders respond to comments from external examiners and produce a formal module evaluation document at the end-of-the-year. Historically, analysis of module evaluations revealed a small number of instances where actions had not been explicitly dealt with in the following module run. Of more consequence here, however, the module evaluations did not explicitly consider the module in relation to the course or the impact of proposed changes on the course. Hence, there was a visible disconnect in relation to tying experienced and enacted curricula back to the planned curricula. In response, a decision was taken to make the module evaluation document less cumbersome and to use these as discussion inputs to the final programme review - the output of which would be a programme evaluation document that explicitly considered the various experienced and enacted curricula in relation to its potential/necessary impact on planned curricula. 
Two significant requirements for staff development also emerged from the programme framework approach. First, it was clear that module leaders tended to 'put the blinkers on' when assigned a module - while all strived to develop excellent curricula, this was often at the expense of the course. This point indicated that more effort was required to communicate the value and importance of the course. Second, more detailed analysis (outside of programme meetings) related to the issues of content and assessment discussed indicated a tendency for module leaders to place too much content in their modules and to over assess. The outcome in relation to these points were (a) to communicate the importance of depth over breath of content (breadth coming from the course curricula) and (b) to introduce policy guidelines related to the number of assessments in any given module. Again, both these issues arose from module leaders have a singular focus set in a context where there was limited holistic focus.

\section{Evaluation of Outcomes}

The review of the literature noted that each of the schools of thought on curriculum development (rational and evolving view) concentrates on vertical alignment at the expense of lateral alignment. The primary points of note from the review were that (a) the schools of thought should not be considered as mutually exclusive and (b) that little advice is offered in relation to the process of ensuring curriculum coherence. What remains is the consideration of the outcomes of application of the framework in relation to these points. Schein (1987) argues that clinical research can be evaluated by (a) using improvement as validation, (b) using clinical data as a source of better theory and (c) the ability to predict the results of intervention. We now present data on the application of the framework and explore these evaluative points.

\subsection{Data collection on improvement}

In order to gather data on the effectiveness and outcomes of the framework, a questionnaire was sent to the 13 module leaders, from which 4 were involved in course in question ( records in bold in Table 2). The results are presented in Table 2. 


\begin{tabular}{|c|c|c|c|c|c|c|c|c|c|}
\hline & & & & \multicolumn{4}{|c|}{ Mechanisms Used } & \multirow[b]{2}{*}{$\begin{array}{l}\text { Identified } \\
\text { Overlaps }\end{array}$} & \multirow[b]{2}{*}{$\begin{array}{l}\text { Actions } \\
\text { Taken? }\end{array}$} \\
\hline $\begin{array}{l}\text { Module } \\
\text { Leader }\end{array}$ & $\begin{array}{c}\text { Module } \\
\text { vs } \\
\text { Course } \\
\text { LO }\end{array}$ & $\begin{array}{l}\text { Courses } \\
\text { Checked }\end{array}$ & $\begin{array}{l}\text { Module } \\
\text { vs } \\
\text { Module }\end{array}$ & $\begin{array}{c}\text { Programme } \\
\text { Meetings }\end{array}$ & $\begin{array}{l}\text { Informal } \\
\text { Meetings }\end{array}$ & Documents & Other & & \\
\hline 1 & Yes & All & Yes & Yes & Yes & Yes & No & Yes & $\begin{array}{c}\text { No } \\
\text { need }\end{array}$ \\
\hline 2 & No & None & Yes & Yes & Yes & No & No & Yes & Yes \\
\hline 3 & Yes & All & Yes & No & Yes & Yes & No & No & No \\
\hline 4 & Yes & All & Yes & No & Yes & Yes & No & No & No \\
\hline 5 & Yes & All & Yes & Yes & Yes & No & No & Yes & Yes \\
\hline 6 & Yes & All & Yes & No & Yes & No & No & No & No \\
\hline 7 & Yes & All & Yes & No & Yes & Yes & No & No & No \\
\hline 8 & Yes & All & Yes & Yes & Yes & Yes & Yes & Yes & $\begin{array}{c}\text { No } \\
\text { need }\end{array}$ \\
\hline 9 & Yes & All & No & No & No & No & No & No & No \\
\hline 10 & Yes & All & Yes & Yes & Yes & Yes & No & Yes & Yes \\
\hline 11 & Yes & One & Yes & Yes & No & No & No & Yes & Yes \\
\hline 12 & Yes & All & Yes & Yes & Yes & Yes & Yes & Yes & Yes \\
\hline 13 & Yes & All & Yes & Yes & Yes & Yes & Yes & No & $\begin{array}{c}\text { No } \\
\text { need }\end{array}$ \\
\hline
\end{tabular}

Table 2 Results from Questionnaire

Of the 13 module leaders interviewed everybody reported that they have checked the link between their module and their programme goals and objectives, through different means. All but one reported that they had informal meetings with people in the programme to ensure curriculum coherence to check lateral coherence across modules. Of the 13 respondents 8 reported having planned programme meetings, while 4 relied mainly on informal meeting and available documentation. One did not report on any of the examined mechanisms of curriculum coherence.

Data suggests that none of the 5 module leaders who did not have formal programme meetings were able to identify overlaps with other modules within their course(s), which may suggest the inexistence of overlaps or unawareness of potential overlaps across modules. Interestingly, all 6 module leaders who had programme meetings (4 of whom were associated with the MSc programme in question) were able to identify overlaps and were willing to take action to rectify them, if necessary.

\subsection{Improvement as Validation}

As curriculum coherence was the aim of this action research. Validation of the success of this programme was examined against the achievement of vertical and lateral coherence. Vertical coherence is conceptualised in terms of the integration between module and course objectives 
in relation to planned, enacted and experienced curricula. The perception of module leaders about the contribution of the framework in this respect was that it provided improvements along several of the dimensions of the framework including communication, coordination and the transfer of knowledge (see Appendix A). For example:

\{Programme meetings\} made me realise/understand more of the specific topics of study of ISM students and how to address the students' interests in lecture. \{Module leader12\}

\{The impact of the programme meetings was\} positive as I could re-shape my modules learning outcomes accordingly that could lead to the revision of module learning objectives and possibly structure \{Module leader 10\}

Most productively, content and delivery matters were increasingly discussed with the view to ensuring that students experience the course as a 'whole' rather that a collection of modules. In addition, as the focus of the programme meetings changed over time from planned and enacted curricula to enacted and experienced curricula (a natural progression as modules were being taught), feedback was encountered that started to impact the planned view. In particular, this related to the need to introduce additional coherence mechanisms that were more 'visible' to the student cohort. Whilst they remain 'work in progress', these mechanisms are the introduction of (a) a synoptic (integrative) examination at the end-of-year and (b) course scenarios, which run across a course of study that modules use as context for assignments.

The latter mechanism relates to improving lateral coherence. Lateral coherence is conceptualised across module aims, objectives and content within planned, enacted or experienced curricula. Here the perceived alignment resulting from the programme meetings was considerable, particularly in relation to dependency management, and transfer of knowledge (again, see Appendix A). Formal programme meetings had a positive effect in (a) facilitating the discussion of integration issues between module leaders during these meetings and, importantly, (b) stimulating informal discussions outside of programme meetings, fostering closer relationships amongst module leaders and comfort about sharing information. For example:

The programme meetings helped me get a better understanding of the other modules and I am actually planning to apply some changes to my module this year after the discussions I had with the other module leaders... It had a positive impact as it facilitated the communication between module leaders and made me aware of the content of other modules. (Module leader 10) 
Moreover, formal programme meetings gave module leaders the opportunity to negotiate the links and redundancies between their modules in a discursive setting and in a constructive way (see also Table 2). For example:

All (my identified) overlaps were complementary therefore not harmful. In one case there was a common lecture with another module. In another, I agreed with the other module leader what the boundaries were. (Module leader12)

I tried to avoid overlapping or take a different approach if there was a similar subject in another module. (Module leader 10)

\subsection{Theory and prediction}

The review of the theory in relation to curriculum development indicated that the rational and evolving schools of thought tended to be considered in a mutually exclusive manner. Even though this difference may result from a requirement for coherent discussion (i.e., the convenience of a dialectic approach), we have noted that the process through which module content is aligned with a course-of-study and module specifications etc. remains 'vague'. To that end, we have adapted and implemented a programme management framework with the expressed intent of removing that vagueness.

The overall usefulness of the framework for designing coherent academic curricula is summarised as follows:

- It exposes the complementarities of the two curricula development views, in practice, and provides a means for maintaining control over the structure of the programme (planned view) while humanising planned curricula by increasing awareness of the fit between modules and by enabling flexibility without threatening the 'wholeness' of programme delivery to students. As a consequence, the programme management activities ensured coherence at the level of planned curricula and enabled the maintenance of such coherence during the enactment of such curricula.

- It allows the actions necessary for ensuring lateral coherence across modules within the same course, both in terms of their goals and learning objectives and in terms of their content.

- Programme management meetings put the topic of curriculum coherence onto the agenda of informal collegial discussions, which enabled lateral coherence to be explored outside the remit of the formalised interactions provided by programme meetings and tools. 
- The formalisation of conversations regarding curriculum coherence helped not only to coordinate these integrative activities but also to document such activities for follow up action and future reference.

While prediction is often considered problematic in the general sphere of interpretive research (Walsham, 1995), we do not wish to make any grand claim. Simply put, the evidence here would indicate that an appropriate framework and action mechanisms for improving vertical and lateral coherence across planned, enacted and experienced curricula will positively influence coherence. Our observation is that quality mechanisms in Higher Education tend to focus on auditable outcome at the (unintended) expense of human interaction. Simply put, our experience has been that it is 'good to talk'. For those on the receiving end, the principal benefits of a more coherent curriculum are those of providing a more rounded and critical mastery over disciplinary knowledge and skills, which prospective IS managers will carry into organisational life.

\subsection{Action Research Validation}

In certain quarters, the action research approach is underutilised and not given much credit as it does not rely on traditional scientific criteria or paradigms (Schein, 1987). As an applied research approach, however, it can provide deep insight into organizational dynamics. In essence, the approach is a particularly appropriate means of 'sensemaking' within organizations - facilitating and capturing the inter-subjective process of constructing, filtering, framing and rendering the subjective into the more tangible (Weick, 1995).

Despite, the lack of widely established criteria for the evaluation of the action research process, the following validation criteria based on Baskerville \& Wood-Harper (1998) were adopted for the evaluation of this action research project. Table 3 lists these criteria alongside the provisions made in this study to ensure its validity and credibility. 


\begin{tabular}{|c|c|}
\hline Validation Criteria & Explanation of How Criteria was Met \\
\hline $\begin{array}{l}\text { Research should be set in a multivariate social } \\
\text { situation }\end{array}$ & $\begin{array}{l}\text { This research was set in the context of a 'real life } \\
\text { scenario' during the development of an MSc programme } \\
\text { curriculum. }\end{array}$ \\
\hline $\begin{array}{l}\text { Observations should be recorded in an interpretive } \\
\text { frame }\end{array}$ & $\begin{array}{l}\text { Two of the authors of this paper drew participant } \\
\text { observations in their dual capacities of module leaders, } \\
\text { and of course manager and director of Programme } \\
\text { respectively. The views of the third author, an 'outsider' to } \\
\text { the action process were used as an 'objective' sounding } \\
\text { board to check against 'native' biases and } \\
\text { misconceptions }\end{array}$ \\
\hline $\begin{array}{l}\text { Researcher-led action should intervene in the } \\
\text { research setting }\end{array}$ & $\begin{array}{l}\text { The authors were involved in design action during the } \\
\text { development of the MSc programme with the view to } \\
\text { ensure curriculum integration and coherence }\end{array}$ \\
\hline $\begin{array}{l}\text { The method of data collection should include } \\
\text { participatory observation }\end{array}$ & $\begin{array}{l}\text { Collected data comprise both participatory observations } \\
\text { of } X \text { and } Y \text {, as well as, the views of the majority of module } \\
\text { leaders involved in the MSc programme }\end{array}$ \\
\hline Changes in the social setting should be studied & $\begin{array}{l}\text { Changes in the social setting are accounted for and } \\
\text { reported in sections } A \text { and } B\end{array}$ \\
\hline $\begin{array}{l}\text { The immediate problem in the social setting is } \\
\text { resolved during the research }\end{array}$ & $\begin{array}{l}\text { Progress towards the resolution of the practical issues } \\
\text { highlighted in table } 1 \text { form the bulk of findings reported in } \\
\text { section } X\end{array}$ \\
\hline $\begin{array}{l}\text { The research should illuminate a theoretical } \\
\text { framework that explains how the actions led to a } \\
\text { favorable outcome }\end{array}$ & $\begin{array}{l}\text { Explanations for the impact of undertaken action on } \\
\text { curricula was drawn on and informed programme } \\
\text { management and curricula development theory (see } \\
\text { section on Discussion) }\end{array}$ \\
\hline
\end{tabular}

Table 3. Action Research Validity Criteria

\section{Conclusions}

This paper has examined curriculum coherence as the means of providing future IS managers with a holistic understanding of the area to better prepare them for their future careers. In response to perceived shortcomings in the literature on the rational and evolving views of curriculum coherence, we have adopted and implemented a programme management framework specifically to improve both vertical and lateral coherence in relation to planned, enacted and experienced curricula. The adoption and implementation of the framework took the form of an action research project, which used clinical fieldwork as the particular form of action research. A Masters-level programme in Information Systems Management provided the context of application.

While the course required significant planned curriculum intervention, it is our experience that poor coherence (or fragmentation over time) is exacerbated by the traditional processes of curriculum design or redesign, which rely heavily on the (singular) interpretation of highly abstract documents, such as module syllabi and course specification. The implemented framework, while meeting the needs of transparency and audit, actively seeks to supplement 
those needs with a human face. Simply put, we have found that improvements in coherence come from face-to-face communication, which actively involves stakeholders in the process. The framework provides a structured context to explore and rectify issues related to communication, coordination, knowledge transfer, dependency management etc. specifically to provide more effective ongoing alignment.

Application of the framework demonstrated improvement in both vertical and lateral coherence. A moderate improvement was found with regard to the vertical alignment between module aims and learning objectives (planned curricula), and of module content and assessment (enacted curricula) to desired course aims and goals. More significant lateral alignment between courses was achieved, where module overlaps were understood and negotiated to avoid redundancy and links between courses were explicitly identified recognized and flagged to students to improve their perception of the overall coherence of the programme.

The overall usefulness of the programme management framework for designing coherent academic curricula was summarized as follows. First, the framework exposed the complementarities of the two curricula development views, in practice, and provided a means for maintaining control over the structure of the programme (planned view) while humanising planned curricula by increasing awareness of the fit between modules and by enabling flexibility without threatening the 'wholeness' of programme delivery to students. In that sense, the programme management activities ensured coherence at the level of planned curricula and enabled the maintenance of such coherence during the enactment of such curricula. Second, the management framework enabled us to make explicit the actions necessary for ensuring lateral coherence across modules within the same course, both in terms of their goals and learning objectives and in terms of their content. Third, the programme management meetings brought the topic of curriculum coherence into the agenda of informal collegial discussions, which enabled lateral coherence to be explored outside the remit of the formalized interactions provided by programme meetings and tools. Fourth, the formalisation of conversations regarding curriculum coherence helped not only to coordinate these integrative activities but also to document such activities for follow up action and future reference. Finally, changes in processes directly or indirectly relating of curriculum design spun off this action research project. Further research in this field has been planned and is currently in the initial phases of its implementation. 


\section{References}

ADAMS D (1988) Extending the educational planning discourse: Conceptual and paradigmatic explorations. Comparative Education Review 32, 400-415.

ALFORD KL, CARTER CA, RAGDALE DJ, RESSEL EK and REYNOLDS CW (2004)

Specification and managed development of information technology curricula. ACM,

ASHE-ERIC (2002) Transforming the curriculum. ASHE-ERIC Higher Education Report.

AWBREY SM (2005) General educational reform as organisational change: Integrating cultural and structural change. The Journal of General Education 54(1), 1-21.

BASKERVILLE R and WOOD-HARPER AT (1998) Diversity in information systems action research methods. European Journal of Information Systems 7(2), 90-107.

BIGGS JB (2002) Aligning teaching and assessment to curriculum objectives. LTSN Imaginative Curriculum web site.

BIGGS JB (2003) Teaching for quality learning at university. Buckingham: Society for Research in Higher Education \& Open University Press.

EWELL PT (1997) Organizing for learning. AAHE Bulletin 50(1), 3-6.

FARMER DW (1999) Course-embedded assessment: A catalyst for realizing the paradigm shift from teaching to learning. Journal of Staff, Program and Organizational Development 16(4), 199-211.

GRUNDY T (1998) Strategy implementation and project management. International Journal of Project Management 16(1), 43-50.

JOHNSON DK and RATCLIFF JL (2004) Creating coherence: The unfinished agenda. New Directions for Higher Education 125(Spring), 85-95.

KNIGHT PT (2001) Complexity and curriculum: A process approach to curriculum-making. Teaching in Higher Education 6(3), 369-381.

LYCETT M, RASSAU A and J. D (2004) Programme management: A critical review. International Journal of Project Management 22(4), 289-299.

MARSH CJ and WILLIS G (1999) Curriculum: Alternative approaches, ongoing issues. Prentice-Hall International, London.

MCELROY W (1996) Implementing strategic change through projects. International Journal of Project Management 14(6), 325-329.

OGC (1999) Managing successful programmes. Office of Government Commerce,

PARKER I (2003) Reconceptualising the curriculum: From commodification to transformation. Teaching in Higher Education 8(4), 529-543. 
PELLEGRINI S (1997) Programme management: Organising project based change. International Journal of Project Management 15(3), 141-149.

SCHEIN EH (1987) The clinical perspective in fieldwork. Sage Publications, Newbury Park, CA.

SUSMAN G (1983) Action research: A sociotechnical systems perspective. In Beyond method: Strategies for social research (MORGAN G, Ed), pp 95-113, Sage, Newbury Park, CA.

VAN DE BOR W, WALLACE G, NAGY G and GARFORTH C (1995) Curriculum development in a european context: An account of a collaborative project. Journal of Agricultural Education and Extension 2(1), 1-16.

WALSHAM G (1995) Interpretive case studies in is research: Nature and method. European Journal of Information Systems 4, 74-81.

WEICK KE (1995) Sensemaking in organisations. Sage Publications, London. 


\section{Appendix A}

\begin{tabular}{|c|c|c|c|c|c|c|}
\hline & Objectives & Outcomes & Framework Goals & Focal View & Type of Alignment & $\begin{array}{l}\text { Levels of } \\
\text { Alignment }\end{array}$ \\
\hline $\begin{array}{l}\text { Induction } \\
\text { Meeting }\end{array}$ & $\begin{array}{l}\text { To provide a deeper } \\
\text { understanding of the } \\
\text { programme objectives and } \\
\text { learning outcomes and the way } \\
\text { each module contributes } \\
\text { towards them }\end{array}$ & $\begin{array}{l}\text { - Improved understanding of } \\
\text { the Programme LOs } \\
\text { preliminary identification of } \\
\text { links between modules } \\
\text { - Improved communication } \\
\text { between actors }\end{array}$ & $\begin{array}{ll}\text { - } & \text { Improve Coordination } \\
\text { - } & \text { Improve dependency } \\
\text { management } \\
\text { - } \\
\text { More effective transfer of } \\
\text { knowledge } \\
\text { - Greater senior } \\
\text { management visibility }\end{array}$ & Rational & Vertical & Enacted Curricula \\
\hline \multirow[t]{3}{*}{$\begin{array}{l}\text { Kick-off } \\
\text { Meeting }\end{array}$} & $\begin{array}{l}\text { To verify that module study } \\
\text { guides match the educational } \\
\text { aims and learning outcomes of } \\
\text { the module and of the } \\
\text { programme }\end{array}$ & $\begin{array}{l}\text { - Improved understanding of } \\
\text { programme LOs and } \\
\text { module LOs }\end{array}$ & $\begin{array}{l}\text { - Improve Coordination } \\
\text { - Improved dependency } \\
\text { management } \\
\text { More effective transfer of } \\
\text { knowledge etc. }\end{array}$ & Rational & Vertical & $\begin{array}{l}\text { Enacted \& Planned } \\
\text { Curricula }\end{array}$ \\
\hline & $\begin{array}{l}\text { To verify/identify links between } \\
\text { modules and avoid } \\
\text { unnecessary overlaps. }\end{array}$ & $\begin{array}{l}\text { - Improved coherence } \\
\text { across modules and the } \\
\text { programme } \\
\text { - Improved programme view } \\
\text { - Improved communication } \\
\text { between actors }\end{array}$ & $\begin{array}{l}\text { - More effective transfer of } \\
\text { knowledge etc. }\end{array}$ & Rational & Lateral & Enacted Curricula \\
\hline & $\begin{array}{l}\text { To coordinate the timing of } \\
\text { assessment }\end{array}$ & $\begin{array}{l}\text { Established coordination } \\
\text { of programme workloads }\end{array}$ & $\begin{array}{l}\text { - Improved dependency } \\
\text { management } \\
\text { More coherent } \\
\text { communication }\end{array}$ & Rational & Lateral & Enacted Curricula \\
\hline
\end{tabular}




\begin{tabular}{|c|c|c|c|c|c|c|}
\hline & To examine assessment load & $\begin{array}{l}\text { - Improved understanding of } \\
\text { student workloads } \\
\text { - } \quad \text { Produced more coherent } \\
\text { programme assessment }\end{array}$ & $\begin{array}{ll}\text { - } & \text { Improved dependency } \\
\text { - } & \text { Greagement senior } \\
\text { - } & \text { management visibility } \\
\text { More effective ongoing } \\
\text { alignment }\end{array}$ & Rational & Vertical \& Lateral & Enacted Curricula \\
\hline & $\begin{array}{l}\text { To discuss other relevant } \\
\text { matters. (industrial scenarios to } \\
\text { be used in class, teaching } \\
\text { strategies, announcements, } \\
\text { etc.) }\end{array}$ & $\begin{array}{l}\text { - Aided on best practices } \\
\text { dissemination } \\
\text { - Enhanced programme } \\
\text { image }\end{array}$ & $\begin{array}{l}\text { - More effective transfer of } \\
\text { knowledge etc }\end{array}$ & Rational & Vertical \& Lateral & $\begin{array}{l}\text { Enacted and } \\
\text { Planned \& } \\
\text { Experienced } \\
\text { Curricula }\end{array}$ \\
\hline \multirow[t]{4}{*}{$\begin{array}{l}\text { Mid-Term } \\
\text { Meeting }\end{array}$} & $\begin{array}{l}\text { To verify that module study } \\
\text { guides match the educational } \\
\text { aims and learning outcomes of } \\
\text { the module and of the } \\
\text { programme }\end{array}$ & $\begin{array}{l}\text { - Improved understanding of } \\
\text { programme LOs and } \\
\text { module LOs }\end{array}$ & $\begin{array}{l}\text { - Improve Coordination } \\
\text { Improved dependency } \\
\text { management } \\
\text { - } \quad \text { More effective transfer of } \\
\text { knowledge etc. }\end{array}$ & Rational & Vertical & $\begin{array}{l}\text { Enacted and } \\
\text { Planned Curricula }\end{array}$ \\
\hline & $\begin{array}{l}\text { To verify/identify links between } \\
\text { modules and avoid } \\
\text { unnecessary overlaps. }\end{array}$ & $\begin{array}{l}\text { - Improved coherence } \\
\text { across modules and the } \\
\text { programme } \\
\text { - Improved programme view } \\
\text { - Improved communication } \\
\text { between actors }\end{array}$ & $\begin{array}{l}\text { More effective transfer of } \\
\text { knowledge etc. }\end{array}$ & Rational \& Evolving & Lateral & Enacted Curricula \\
\hline & $\begin{array}{l}\text { To coordinate the timing of } \\
\text { assessment }\end{array}$ & $\begin{array}{l}\text { - Established coordination } \\
\text { of programme workloads }\end{array}$ & $\begin{array}{ll}\text { - Improved dependency } \\
\text { management } \\
\text { - } \quad \text { More coherent } \\
\text { communication }\end{array}$ & Rational \& Evolving & Lateral & Enacted Curricula \\
\hline & To examine assessment load & $\begin{array}{l}\text { - Improved understanding of } \\
\text { - } \quad \text { Prudent workloads } \\
\text { programmed more coherent } \\
\text { - Aided on adopting best } \\
\text { practices }\end{array}$ & $\begin{array}{ll}\text { - } & \text { Improved dependency } \\
\text { - } & \text { Greagementer senior } \\
\text { management visibility } \\
\text { - } \\
\text { More effective ongoing } \\
\text { alignment }\end{array}$ & Rational \& Evolving & Vertical \& Lateral & $\begin{array}{l}\text { Enacted and } \\
\text { Planned Curricula }\end{array}$ \\
\hline
\end{tabular}




\begin{tabular}{|c|c|c|c|c|c|c|}
\hline & $\begin{array}{l}\text { To discuss other relevant } \\
\text { matters. (industrial scenarios to } \\
\text { be used in class, teaching } \\
\text { strategies, announcements, } \\
\text { etc.) }\end{array}$ & $\begin{array}{l}\text { - } \quad \text { Aided on best practices } \\
\text { dissemination } \\
\text { - Enhanced programme } \\
\text { image }\end{array}$ & $\begin{array}{l}\text { - More effective transfer of } \\
\text { knowledge etc }\end{array}$ & Rational \& Evolving & Vertical \& Lateral & $\begin{array}{l}\text { Experienced } \\
\text { Curricula }\end{array}$ \\
\hline $\begin{array}{l}\text { Module Review } \\
\text { Meeting }\end{array}$ & $\begin{array}{l}\text { To monitor that the changes } \\
\text { specified in the Kick-off and } \\
\text { Mid-term programme meetings } \\
\text { are properly addressed }\end{array}$ & $\begin{array}{l}\text { Ensured to meet kick-off } \\
\text { and mid-term meetings } \\
\text { goals }\end{array}$ & $\begin{array}{l}\text { - } \quad \text { More coherent } \\
\text { communication }\end{array}$ & Evolving & Lateral & $\begin{array}{l}\text { Enacted and } \\
\text { Planned Curricula }\end{array}$ \\
\hline \multirow{5}{*}{$\begin{array}{l}\text { Final Programme } \\
\text { Meeting }\end{array}$} & To evaluate the programme & \multirow{5}{*}{ In process } & & Rational \& Evolving & Vertical \& Lateral & $\begin{array}{l}\text { Enacted, Planned } \\
\text { and Experienced } \\
\text { Curricula }\end{array}$ \\
\hline & $\begin{array}{l}\text { To evaluate modules within the } \\
\text { programme }\end{array}$ & & & Rational \& Evolving & Vertical \& Lateral & $\begin{array}{l}\text { Enacted, Planned } \\
\text { and Experienced } \\
\text { Curricula }\end{array}$ \\
\hline & $\begin{array}{l}\text { To identify possible changes to } \\
\text { module content }\end{array}$ & & & Rational \& Evolving & Vertical \& Lateral & $\begin{array}{l}\text { Enacted, Planned } \\
\text { and Experienced } \\
\text { Curricula }\end{array}$ \\
\hline & $\begin{array}{l}\text { To identify possible changes to } \\
\text { programme and/or module } \\
\text { specifications }\end{array}$ & & & Rational \& Evolving & Vertical \& Lateral & $\begin{array}{l}\text { Enacted, Planned } \\
\text { and Experienced } \\
\text { Curricula }\end{array}$ \\
\hline & $\begin{array}{l}\text { To suggest changes to } \\
\text { assessment methods }\end{array}$ & & & Rational \& Evolving & Lateral & $\begin{array}{l}\text { Enacted, Planned } \\
\text { and Experienced } \\
\text { Curricula }\end{array}$ \\
\hline
\end{tabular}

